\title{
Development of Indirect Competitive ELISA and Visualized Multicolor ELISA Based on Gold Nanorods Growth for the Determination of Zearalenone
}

\author{
Tianyu Ma ${ }^{1,2}$, Kaixin Liu ${ }^{1,2}$, Xiao Yang ${ }^{1,2}$, Jingying Yang ${ }^{1,2}$, Mingfei Pan ${ }^{1,2, *}$ and Shuo Wang ${ }^{1,2}$ \\ 1 State Key Laboratory of Food Nutrition and Safety, Tianjin University of Science \& Technology, \\ Tianjin 300457, China; maty1128@126.com (T.M.); Liukx2019@163.com (K.L.); yangx2021@126.com (X.Y.); \\ yangjy0823@126.com (J.Y.); s.wang@tust.edu.cn (S.W.) \\ 2 Key Laboratory of Food Nutrition and Safety, Ministry of Education of China, \\ Tianjin University of Science and Technology, Tianjin 300457, China \\ * Correspondence: panmf2012@tust.edu.cn; Tel.: +86-022-6091-2493
}

check for updates

Citation: Ma, T.; Liu, K.; Yang, X.; Yang, J.; Pan, M.; Wang, S.

Development of Indirect Competitive ELISA and Visualized Multicolor ELISA Based on Gold Nanorods Growth for the Determination of Zearalenone. Foods 2021, 10, 2654. https://doi.org/10.3390/ foods10112654

Academic Editor: Andrew G. Gehring

Received: 6 October 2021

Accepted: 28 October 2021

Published: 2 November 2021

Publisher's Note: MDPI stays neutral with regard to jurisdictional claims in published maps and institutional affiliations.

Copyright: (c) 2021 by the authors. Licensee MDPI, Basel, Switzerland. This article is an open access article distributed under the terms and conditions of the Creative Commons Attribution (CC BY) license (https:/ / creativecommons.org/licenses/by/ $4.0 /)$.

\begin{abstract}
In this study, a zearalenone (ZEN) hapten was designed and prepared against the mycotoxin ZEN, and the original coating ZEN-ovalbumin (ZEN-OVA) was prepared by conjugation with OVA. Based on the gold nanorods (AuNRs) of uniform size and stable properties synthesized by the seedmediated method, the indirect competitive enzyme-linked immunosorbent assay (ic-ELISA) and the AuNRs growth-based multicolor ELISA for detecting ZEN toxin were further established. Under the optimal experimental conditions, the coating amount of ZEN-OVA: $0.025 \mu \mathrm{g} /$ well, antibody $\mathrm{Ab}$ ) dilution factor: 32,000 times, blocking solution: 0.5\% skimmed milk powder, enzyme-labeled secondary $\mathrm{Ab}$ diluted 10,000 times, and a $\mathrm{pH}$ of the PBS buffer at 7.4, the sensitivity $\left(I C_{50}\right)$ of the established ic-ELISA for ZEN detection reached $0.85 \pm 0.04 \mu \mathrm{g} / \mathrm{L}$, and the limit of detection $\left(I C_{15}\right)$ reached $0.22 \pm 0.08 \mu \mathrm{g} / \mathrm{L}$. In the multicolor ELISA based on the growth of AuNRs, as the content of ZEN increased, the mixed solution exhibited a significant color change from brownish red to colorless. ZEN concentration as low as $0.1 \mu \mathrm{g} / \mathrm{L}$ can be detected by the naked eye (brown red to dark gray). This study provided an effective analysis strategy for the rapid screening and accurate monitoring of the ZEN contaminant in foods.
\end{abstract}

Keywords: zearalenone; gold nanorods; indirect competitive ELISA; visualized multicolor ELISA

\section{Introduction}

Zearalenone (ZEN) is a nonsterol estrogen mycotoxin mainly produced by Fusarium genera, which is widely found in grain crops, such as corn, wheat, and barley [1,2]. The degree of contamination of food crops by Fusarium mainly depends on the moisture and temperature conditions; the optimal growth temperature for Fusarium is between 24 and $32{ }^{\circ} \mathrm{C}$ and the optimal humidity is $40 \%$ [3]. Therefore, in areas with sufficient rainfall and high relative humidity, cereals are likely to be contaminated with Fusarium in all steps of production, storage, and processing [4]. ZEN can cause excessive estrogen syndrome in animals such as pig, poultry, and humans, as well as immunotoxicity, genotoxicity, and suspected carcinogenicity [5,6]. It has been reported that the potential etiological mechanism of breast cancer involves changes in the cytochrome P450 (CYP) enzyme, which is related to ZEN [7]. Yu et al. have demonstrated that the ZEN on 2,3,7,8-Tetrachlorodibenzop-dioxin (TCDD)-induced CYP1A1 activity and gene expression involved the estrogen receptor pathway [8]. In addition, due to its similar structure to endogenous estrogen, ZEN can show estrogen activity in vivo and competitively bind with estrogen receptors, thus affecting estrogen secretion in humans or animals, resulting in reproductive organ abnormalities, infertility, abortion, and other diseases [9-11]. At present, many countries and organizations have regulated the maximum residue levels (MRLs) of ZEN in foods, although a consistent standard has not yet been obtained (European Union: $20-400 \mu \mathrm{g} / \mathrm{kg}$ 
in different types of foods, Russia: $1000 \mu \mathrm{g} / \mathrm{kg}$ in hard wheat, flour and wheat germ; China: $60 \mu \mathrm{g} / \mathrm{kg}$ in cereals and its products) [12-14]. Therefore, the development of effective strategies for ZEN detection in foods is of great significance for protecting the health of humans and animals.

Currently, traditional instrumental methods based on liquid chromatography (LC), gas chromatography (GC), and mass spectrometry (MS) have been widely applied in the detection of ZEN contaminant in foods and animal feed samples [15-20]. However, these techniques require sophisticated instruments, professional and experienced operators, and long test time, which limits the practical application to a certain extent. Engvall and Perlmann achieved the quantitative detection of a solid phase enzyme immunoassay for the first time, marking the successful construction of an enzyme linked immunosorbent assay (ELISA) [21,22]. The ELISA has the characteristics of simple operation, high specificity, and low cost, and has gradually become the mainstream technology in the field of rapid detection $[23,24]$. Improving the sensitivity and lowering the detection limit of ELISA can promote the further application of this effective technology $[25,26]$. Signal amplification has been demonstrated by many researchers to improve the sensitivity of ELISA. In particular, the introduction of various nanomaterials has further improved the performance of traditional ELISA. For example, Zhang et al. synthesized CdTe/CdS/ZnS quantum dots (QDs) in the aqueous phase and developed a fluorescent immunoassay (FLISA) for detecting ZEN in corn [27]. Xiong et al. reported an advanced enzyme-assisted etching method in which gold nanorods (AuNRs) were applied as the signal carrier for aflatoxin $\mathrm{B}_{1}\left(\mathrm{AFB}_{1}\right)$ in corn samples to amplify the ELISA signal [28]. Liu et al. constructed a horseradish peroxidase (HRP)-mediated ratio fluorescence ELISA based on gold and silver bimetallic nanoclusters (Au-AgNCs) to detect zearalenone, which significantly improved the detection limit [29].

In this study, we successfully prepared the ZEN hapten and ZEN coating antigen (ZEN-ovalbumin (ZEN-OVA)) and developed an indirect competitive-ELISA (ic-ELISA) strategy using monoclonal antibodies (anti-ZEN-Abs) with high sensitivity and specificity. On this basis, a visual multicolor ELISA was developed based on alkaline phosphatase (AP) converting ascorbic acid-phosphate $(\mathrm{VcP})$ to ascorbic acid $(\mathrm{Vc})$ to control the growth of AuNRs. Compared with traditional ic-ELISA for ZEN, the visualized multicolor ELISA based on AuNRs growth offered a more convenient and intuitive strategy for the detection of ZEN contaminant (Scheme 1).

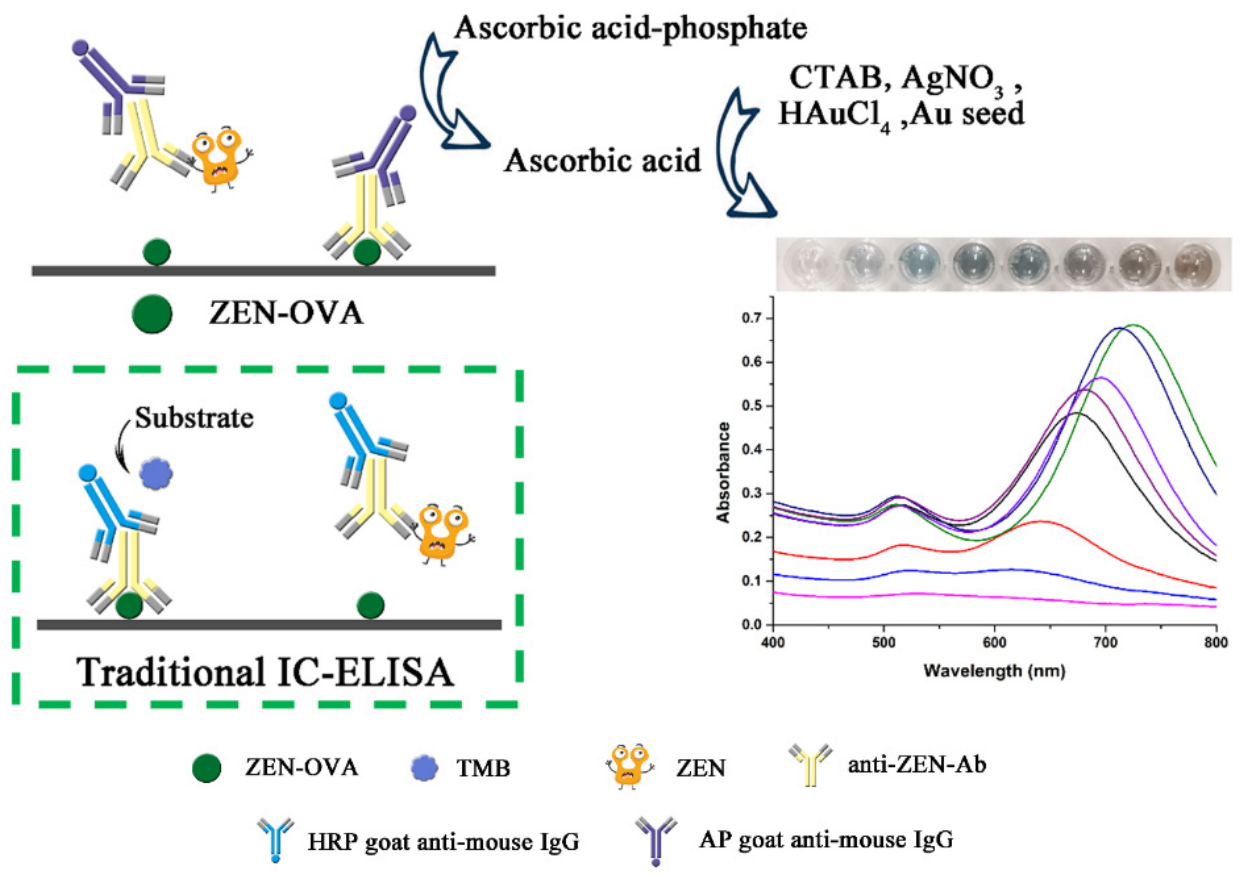

Scheme 1. Procedure of the visualized AuNRs growth-based multicolor ELISA for ZEN detection compared with the traditional ic-ELISA. 


\section{Materials and Methods}

\subsection{Material and Apparatus}

Hexadecyl trimethyl ammonium bromide (CTAB, 99\%) was purchased from Solarbio (Beijing, China). Chloroauric acid $\left(\mathrm{HAuCl}_{4}\right)$ for the synthesis of AuNRs was obtained from Sigma-Aldrich (St. Louis, MO, USA). Silver nitrate $\left(\mathrm{AgNO}_{3}\right), \mathrm{Vc}, \mathrm{VcP}$, and sodium borohydride $\left(\mathrm{NaBH}_{4}\right)$ for the synthesis of AuNRs, 1-ethyl-3-[3-(dimethylamino) propyl] carbodimide (EDC) and OVA for the synthesis of the conjugate of ZEN-OVA were obtained from the Sinopharm Chemical Reagent Co., Ltd. (Shanghai, China). Pyridine and carboxymethoxylamine (CMO) were purchased from TCI Development Co. Ltd. (Shanghai, China). The anti-ZEN monoclonal antibody (anti-ZEN-Ab, $1.0 \mathrm{mg} / \mathrm{mL}$ ) was purchased from Shandong Lvdu Biotechnology Co. Ltd. (Shandong, China). 3,3,5,5-tetramethylbenzidine (TMB), HRP goat anti-mouse IgG conjugated $(1.0 \mathrm{mg} / \mathrm{mL})$, AP goat anti-mouse IgG conjugated $(3.5 \mathrm{mg} / \mathrm{mL}), \mathrm{AFB}_{1}, \mathrm{ZEN}$ and the structural analogues ( $\alpha$-zearalenol, $\alpha$ zearalanol, $\beta$-zearalenol, zearalanone, $\beta$-zearalanol $)(1.0 \mathrm{mg} / \mathrm{L})$ were also purchased from Sigma-Aldrich (St. Louis, MO, USA). T-2 toxin, ochratoxin A (OTA), and fumonisin $\mathrm{B}_{2}$ $\left(\mathrm{FB}_{2}\right)$ were purchased from Toronto Research Chemicals (Toronto, ON, Canada).

The microplate reader for reading the absorbance values was purchased from Thermo Fisher Scientific (Waltham, MA, USA). The UV-visible spectrophotometer (Cary 50 Bio) was obtained from Varian (Salt Lake, CA, USA). The 96-well polystyrene microplates, multichannel pipettes $(100-300 \mu \mathrm{L})$, and single-channel pipettes $(2.5-1000 \mu \mathrm{L})$ were obtained from Thermo Fisher Scientific (Waltham, MA, USA). The transmission electron microscopy (TEM) images were obtained from Talos G2 200X electronic microscope (Thermo Fisher Scientific (Waltham, MA, USA). A vortex machine (HQ-60) was purchased from North Tongzheng Biotechnology Development Company (Beijing, China). Milli-Q Ultrapure Water System was purchased from Milli-Q Millipore, (Bedford, MA, USA).

\subsection{Preparation of the Coating Antigen-The Conjugate of ZEN-OVA}

The preparation method of ZEN-CMO was modified according to the previous literature [30]. Briefly, $10.0 \mathrm{mg}$ of ZEN was dissolved in $200 \mu \mathrm{L}$ of methanol and mixed well. Then, $20.0 \mathrm{mg}$ of $\mathrm{CMO}$ and $1.0 \mathrm{~mL}$ of anhydrous pyridine were sequentially added into the above mixed solution. The mixture was stirred and reacted under nitrogen protection for $24 \mathrm{~h}$. After the reaction was completed, the mixture was placed in a vacuum oven at $80{ }^{\circ} \mathrm{C}$ to remove pyridine and store at $4{ }^{\circ} \mathrm{C}$ for later use. We mixed $9.78 \mathrm{mg}$ of the above conjugate ZEN-CMO and $14.0 \mathrm{mg}$ of EDC, successively dissolved it in $1.0 \mathrm{~mL}$ of DMF, and stirred and activated it overnight at $4{ }^{\circ} \mathrm{C}$. In total, $10.0 \mathrm{mg}$ of OVA was dissolved in $2.0 \mathrm{~mL}$ of $\mathrm{NaHCO}_{3}(130 \mathrm{mmol} / \mathrm{L})$ and precooled. The activated product was added dropwise under ice bath conditions. Two hours later, the product was placed under $4{ }^{\circ} \mathrm{C}$ overnight and dialyzed against PBS buffer solution for $72 \mathrm{~h}$ and stored at $-20{ }^{\circ} \mathrm{C}$.

\subsection{Test Procedure of ic-ELISA}

The antigen ZEN-OVA was dissolved in the coating solution and mixed evenly. The mixture was added to a microplate $(0.025,0.05,0.1 \mu \mathrm{g} /$ well, $100 \mu \mathrm{L} /$ well $)$, and incubated overnight at $4{ }^{\circ} \mathrm{C}$. After washing the plate with PBST ( $0.01 \mathrm{~mol} / \mathrm{L}$ PBS and $0.1 \%$ Tween-20) 3 times, the blocking solution (PBS containing $0.5 \%$ skimmed milk powder, $200 \mu \mathrm{L} /$ well) was added, and we incubated the mixture at $37^{\circ} \mathrm{C}$ for $1 \mathrm{~h}$. After washing, the mixture of ZEN standards were diluted to different concentrations $(50 \mu \mathrm{L})$ and anti-ZEN Ab $(50 \mu \mathrm{L})$ was added and reacted at $37^{\circ} \mathrm{C}$ for $1 \mathrm{~h}$. Then, $100 \mu \mathrm{L}$ of HRP goat anti-mouse IgG was added into each well and incubated for $0.5 \mathrm{~h}$. After washing the plate with PBST 5 times, $100 \mu \mathrm{L}$ of the TMB substrate solution was added into each well. After incubation for $15-30 \mathrm{~min}$, the reaction was terminated with $50 \mu \mathrm{L}$ of $\mathrm{H}_{2} \mathrm{SO}_{4}(1.25 \mathrm{~mol} / \mathrm{L})$. Then, the absorbance was measured at $450 \mathrm{~nm}$ using a microplate reader. 


\subsection{Specificity of ic-ELISA}

The specificity of Abs is related to the structure of the antigenic determinant and is expressed as the cross-reactivity rate. Ten mycotoxins including ZEN, five structural analogs of ZEN ( $\alpha$-zearalenol, $\beta$-zearalenol, $\alpha$-zearalanol, $\beta$-zearalanol, and zearalanone), and four common mycotoxins $\left(\mathrm{AFB}_{1}, \mathrm{OTA}, \mathrm{T}-2\right.$ toxin, and $\left.\mathrm{FB}_{2}\right)$ were used as competing standards to determine the cross-reactivity rate to anti-ZEN-Ab by ic-ELISA. The mentioned analytes were diluted with PBS to the following concentrations (1000, 333.3, 111.11, 37.03, $12.34,4.11,1.37,0.45,0.15,0.05$, and $0.016 \mu \mathrm{g} / \mathrm{L}$ ). The following equation was used to calculate the cross-reaction rate.

$$
\begin{gathered}
\mathrm{CR}(\%)=\mathrm{IC}_{50}(50 \% \text { inhibitory concentration }(\mathrm{ZEN})) / \mathrm{IC}_{50}(50 \% \text { inhibitory } \\
\text { concentration (competitor) }) \times 100 \%
\end{gathered}
$$

\subsection{AuNR Growth-Based Multicolor ELISA for ZEN}

Preparation of AuNRs seed liquid. The AuNRs were synthesized by the seedmediated method in this study. A total of $1.0 \mathrm{~mL}$ of CTAB $(0.2 \mathrm{~mol} / \mathrm{L})$ and $1.0 \mathrm{~mL}$ of $\mathrm{HAuCl}_{4}(0.5 \mathrm{mmol} / \mathrm{L})$ were added into a round-bottom flask and mixed thoroughly. Then, $120 \mu \mathrm{L}$ of $\mathrm{NaBH}_{4}(0.01 \mathrm{~mol} / \mathrm{L})$ was added and stirred gently for $2 \mathrm{~min}$. The obtained mixture was used as the seed liquid for AuNR growth.

Effect of Vc dosage on AuNR growth. The mixed solution containing $125 \mu \mathrm{L}$ of $\mathrm{CTAB}(0.2 \mathrm{~mol} / \mathrm{L}), 1.5 \mu \mathrm{L}$ of $\mathrm{AgNO}_{3}(0.01 \mathrm{~mol} / \mathrm{L})$, and $12.5 \mu \mathrm{L}$ of $\mathrm{HAuCl}_{4}(0.01 \mathrm{~mol} / \mathrm{L})$ was added to each well of the enzyme-labeled plate. After mixing, the $\mathrm{Vc}(0.01 \mathrm{~mol} / \mathrm{L})$ solution of different volumes $(0-20 \mu \mathrm{L})$ was added to control the total volume of the solution to $240 \mu \mathrm{L}$. Next, $10 \mu \mathrm{L}$ of the seed solution was added to mediate the production of AuNRs. After mixing evenly, the mixture was incubated at room temperature for $1 \mathrm{~h}$, and UV absorption spectra of the grown AuNRs were recorded.

Procedure of visualized multicolor ELISA based on AuNR growth. The encapsulation process of the ZEN-OVA conjugate and its competitive binding with anti-ZEN Abs were the same as ic-ELISA. The difference was that $100 \mu \mathrm{L}$ of AP-goat anti-mouse IgG diluted 10,000 times with Tris- $\mathrm{HCl}$ buffer $(1 \mathrm{mmol} / \mathrm{L} \mathrm{pH} \mathrm{7.4)}$ ) was added to each well. After incubation at $37^{\circ} \mathrm{C}$ for $30 \mathrm{~min}$ and full washing, $80 \mu \mathrm{L}$ of $\mathrm{VcP}(15 \mathrm{mmol} / \mathrm{L})$ was added into each well. After full mixing, the mixture was incubated at $37^{\circ} \mathrm{C}$ for $1 \mathrm{~h}$. Then, $50 \mu \mathrm{L}$ of the above reaction solution was mixed evenly with the solution containing $125 \mu \mathrm{L}$ of $\mathrm{CTAB}(0.2 \mathrm{~mol} / \mathrm{L}), 1.5 \mu \mathrm{L}$ of $\mathrm{AgNO}_{3}(0.01 \mathrm{~mol} / \mathrm{L})$, and $12.5 \mu \mathrm{L}$ of $\mathrm{HAuCl}_{4}(0.01 \mathrm{~mol} / \mathrm{L})$ and controlled to $240 \mu \mathrm{L}$ with ultrapure water. After $10 \mu \mathrm{L}$ of seed solution was added, the mixture was incubated at room temperature for $1 \mathrm{~h}$ and tested by naked eye and UV absorption spectroscopy.

\section{Results and Discussion}

\subsection{Preparation and Characterization of ZEN-CMO and ZEN-OVA Conjugate}

In this study, the prepared ZEN-CMO (Mr: 391.28) was analyzed by mass spectrometry (Figure S1). In an anionic environment, the characteristic ion peaks of ZEN-CMO $[\mathrm{M}-1]^{-}$at 390.40 and $[2 \mathrm{M}-1]^{-}$at 781.80 were observed, proving the successful preparation of the hapten ZEN-CMO with acceptable purity. The ZEN-CMO product was further conjugated with OVA to obtain ZEN-OVA conjugate, the concentration of which was determined to be $3.85 \mathrm{mg} / \mathrm{mL}$ by a commercial BCA kit. Furthermore, the prepared ZEN-OVA conjugate was tested for its conjugate ability to anti-ZEN Abs (Table S1). When the Abs was diluted 16,000 times, the $O D_{450}$ value reached 1.253, and the inhibition rate reached $98.92 \%$, indicating the successful coupling of ZEN-CMO and OVA, and the obtained ZEN-OVA conjugate could be used for subsequent immunoassay experiments.

\subsection{Conditions Optimization of Traditional ELISA}

Dilution times of ZEN-OVA conjugate and anti-ZEN Abs. Different amounts of ZEN-OVA conjugate were coated on a 96-well microtiter plate to optimize the dilution 
times through ic-ELISA. According to the results shown in Table S2, when the coating amount of the ZEN-OVA conjugate was $0.1 \mu \mathrm{g} /$ well and the Ab dilution factor was 64,000 , the $\mathrm{OD}_{450}$ value reached 0.858 , and the $\mathrm{IC}_{50}$ was $2.68 \mu \mathrm{g} / \mathrm{L}$. When the coating amount was $0.05 \mu \mathrm{g} /$ well and $0.025 \mu \mathrm{g} /$ well, the dilution factor was 32,000, the corresponding $\mathrm{OD}_{450}$ and $\mathrm{IC}_{50}$ values were 1.078 and $0.793,1.06 \mu \mathrm{g} / \mathrm{L}$ and $0.85 \mu \mathrm{g} / \mathrm{L}$, respectively. It can be clearly seen that the $\mathrm{IC}_{50}$ increased with the increase in the coating amount of ZEN-OVA, which was because the excessive amount of ZEN-OVA bound to the Ab led to the decrease in detection sensitivity. When the coating amount was $0.025 \mu \mathrm{g} /$ well and the Ab dilution factor was 32,000 , the color development was relatively stable and the $\mathrm{IC}_{50}$ reached the lowest value, which was selected as the optimal condition for subsequent experiments.

Blocking Solution. The blocking solution was applied to block the excess binding sites in the micropores. A higher concentration of the blocking solution may affect the subsequent binding between the antigen and $\mathrm{Ab}$, thereby reducing the sensitivity of the method. In the study, the $\mathrm{IC}_{50}$ values of the ic-ELISA method using different concentrations $(0.5 \%$ and $1 \%)$ of skimmed milk powder as the blocking solution were compared (Table S3). The $0.5 \%$ skimmed milk powder had an $\mathrm{IC}_{50}$ of $0.85 \mu \mathrm{g} / \mathrm{L}$, less than using $1 \%$ skimmed milk powder $(2.41 \mu \mathrm{g} / \mathrm{L})$, which was selected as the blocking solution.

pH value of PBS diluent. PBS buffers with different $\mathrm{pH}$ values $(5.7,7.4$, and 8.5$)$ were used for Ab dilution and ic-ELISA tests were performed (Table S4). When PBS was used at $\mathrm{pH} 7.4$, the $\mathrm{IC}_{50}$ value was only $0.85 \mu \mathrm{g} / \mathrm{L}$, which was significantly lower than that obtained at $\mathrm{pH} 5.7$ and $8.5(2.95 \mu \mathrm{g} / \mathrm{L}$ and $1.86 \mu \mathrm{g} / \mathrm{L})$. At this time, the corresponding absorbance value $(\lambda=450 \mathrm{~nm})$ was also significantly higher than the other two $\mathrm{pH}$ values, because the acidic or alkaline environment affected the binding reaction between the antigen and $\mathrm{Ab}$ as well as enzyme-labeled antibody, resulting in the reduction in detection sensitivity. Therefore, a PBS buffer of $\mathrm{pH} 7.4$ was chosen as a diluent for Ab and ZEN standards.

\section{3. ic-ELISA Standard Curve}

Under the optimal conditions: coating amount of ZEN-OVA $0.025 \mu \mathrm{g} /$ well, Ab dilution 32,000 times, blocking solution $0.5 \%$ skim milk powder in PBS, PBS buffer (pH 7.4) as diluent, the standard curve of ic-ELISA for ZEN is shown in Figure 1. The sensitivity $\left(\mathrm{IC}_{50}\right)$ and limit of detection $\left(\mathrm{IC}_{15}\right)$ reached $0.85 \pm 0.04 \mu \mathrm{g} / \mathrm{L}$ and $0.22 \pm 0.08 \mu \mathrm{g} / \mathrm{L}$, indicating that this method can provide accurate and sensitive analysis for the ZEN toxin.

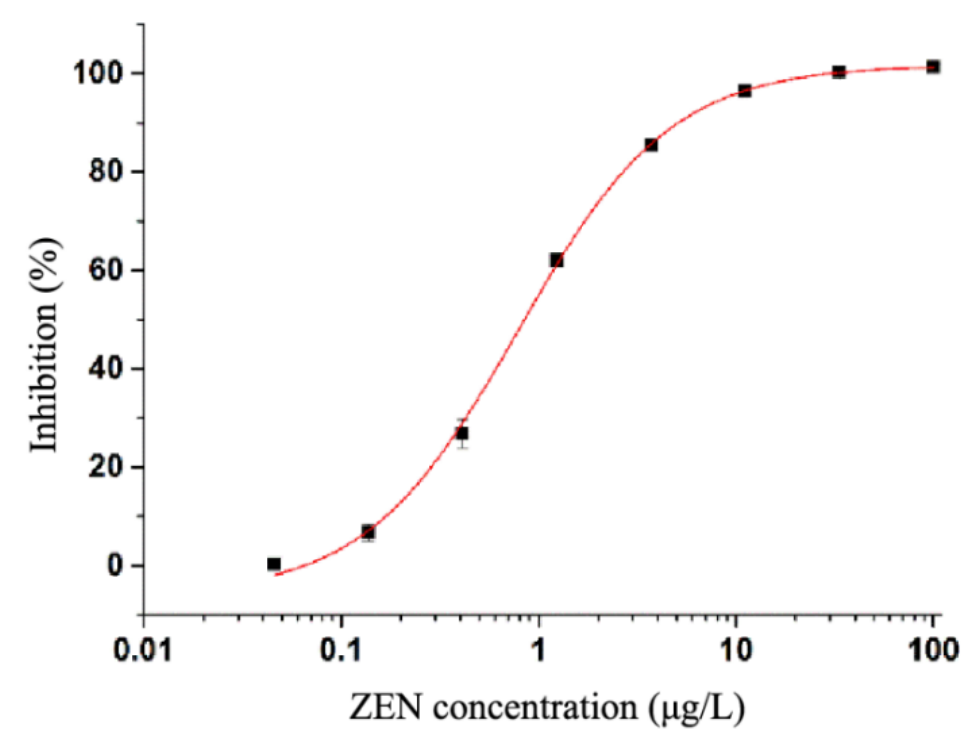

Figure 1. Standard curve of ZEN by ic-ELISA.

\subsection{Specificity of Traditional ELISA}

In order to evaluate the specificity of the established ic-ELISA method to ZEN, five ZEN structural analogs ( $\alpha$-zearalanol, $\beta$-zearalanol, $\alpha$-zearalenol, $\beta$-zearalenol, and zear- 
alenone) and four common mycotoxins ( $\mathrm{AFB}_{1}, \mathrm{OTA}_{\mathrm{A}} \mathrm{FB}_{2}$, and $\mathrm{T}-2$ toxin) were selected and analyzed (Table 1). The cross-reaction rate of four structural analogs $\alpha$-zearalanol, $\beta$-zearalanol, $\alpha$-zearalenol, and $\beta$-zearalenol were $35.27 \%, 45.70 \%, 29.72 \%$ and $17.93 \%$, respectively; the cross-reaction rate of zearalenone was only $1.58 \%$; and there was no obvious cross-reaction with other mycotoxins. These results proved that the established ic-ELISA method had high specificity.

Table 1. Cross-reacting of ZEN with other mycotoxins.

\begin{tabular}{|c|c|c|c|}
\hline Determinand & Structure & $\mathrm{IC}_{50}(\mu \mathrm{g} / \mathrm{L})$ & Cross-Reaction Rate \\
\hline Zearalenone & & 0.85 & 100 \\
\hline$\alpha$-Zearalanol & & 2.41 & 35.27 \\
\hline$\beta$-Zearalanol & & 1.86 & 45.70 \\
\hline$\alpha$-Zearalenol & & 2.86 & 29.72 \\
\hline$\beta$-Zearalenol & & 4.74 & 17.93 \\
\hline Zearalanone & & 53.79 & 1.58 \\
\hline $\mathrm{AFB}_{1}$ & & $>1000$ & $<0.01$ \\
\hline OTA & & $>1000$ & $<0.01$ \\
\hline $\mathrm{FB}_{2}$ & & $>1000$ & $<0.01$ \\
\hline $\mathrm{T}-2$ toxin & & $>1000$ & $<0.01$ \\
\hline
\end{tabular}




\subsection{Multicolor ELISA Based on AuNRs Growth}

The AuNRs used in the study were prepared by a traditional seed-mediated method. The amount of $\mathrm{Vc}_{\mathrm{c}}$ had a very important effect on the morphology and properties of the prepared AuNPs. Figure 2a shows the results of AuNRs obtained under different Vc solution additions. When a small amount of Vc solution was added (No. 1-6), the mixed solution appeared yellow, and the corresponding UV-visible absorption spectrum had a significant absorption peak at $400 \mathrm{~nm}$, which was the characteristic absorption of $\mathrm{HAuCl}_{4}$. With the increase in Vc solution volume, the color of the solution gradually lightened. When the added amount was $12.0 \mu \mathrm{L}$, the solution was colorless by naked eye observation. Meanwhile, no significant absorption was observed in the wavelength range greater than $500 \mathrm{~nm}$. This was because when the amount of $\mathrm{Vc}_{\mathrm{c}}$ was low, only $\mathrm{Au}$ (III) was reduced to colorless $\mathrm{Au}(\mathrm{I})$ (No. 7). When the amount of $\mathrm{Vc}_{\mathrm{c}}$ further increased, a new and gradually enhanced UV absorption peak was formed at 500-800 nm, indicating that AuNRs gradually grew (No. 8-11), which also proved that the Vc supplemental level played a very important role in regulating AuNRs growth.

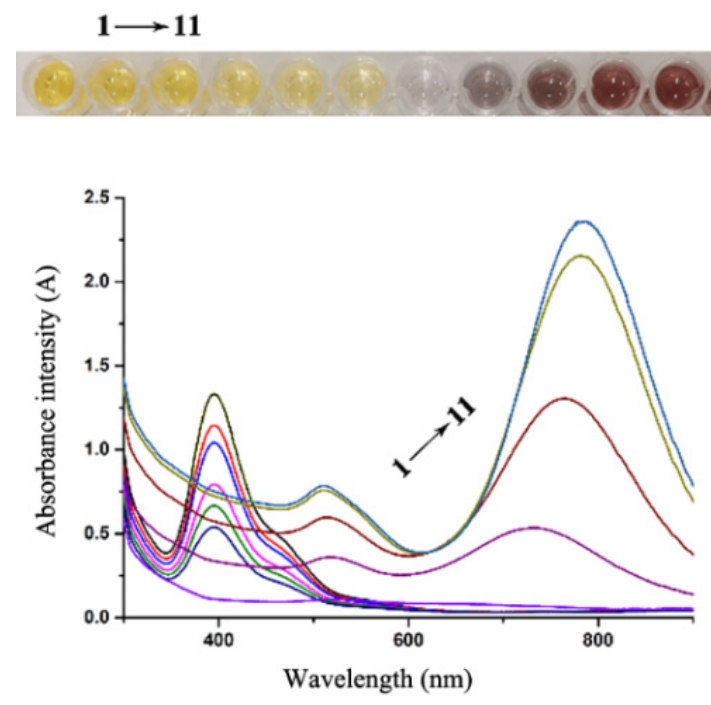

(a)

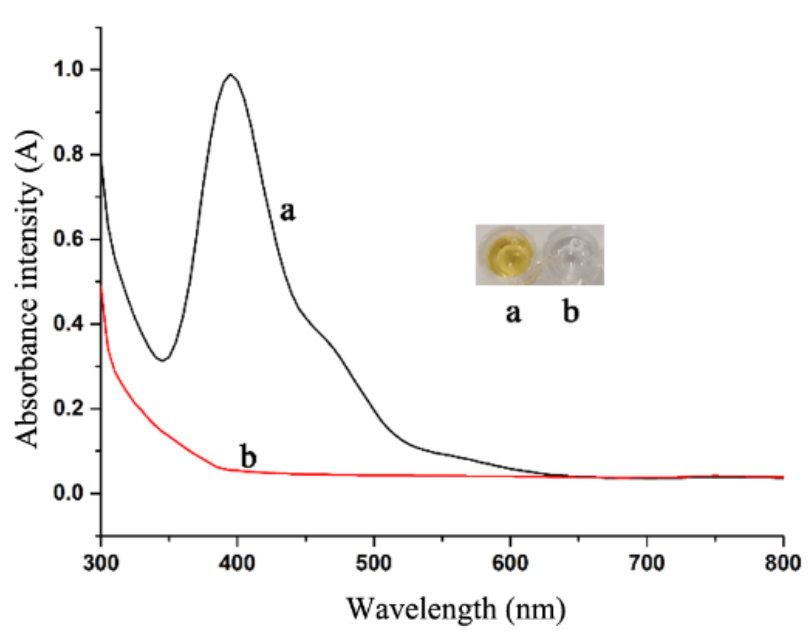

(b)

Figure 2. (a) UV-visible absorption spectra of AuNRs grown with different volumes of Vc; (b) UV-vis spectra and visual results of the AuNRs growth solution before and after adding excessive VcP (a: before; b: after).

$\mathrm{AP}$ can induce the conversion of $\mathrm{VcP}$ to $\mathrm{Vc}$ and then promote the growth of AuNRs. Figure $2 \mathrm{~b}$ shows the UV absorption spectra and visual results of the AuNR growth solution before and after the addition of excessive VcP. It was clearly observed that the addition of $\mathrm{VcP}$ changed the growth solution from yellow (curve a) to colorless (curve b). In addition, when excessive $\mathrm{VCP}$ was added, there was no absorption peak in the wavelength range of $500-800 \mathrm{~nm}$, indicating that $\mathrm{VcP}$ could also reduce $\mathrm{Au}$ (III) to $\mathrm{Au}$ (I) but could not promote the growth of AuNRs. It was confirmed that the conversion of $\mathrm{VCP}_{\mathrm{CP}} \mathrm{V}_{\mathrm{c}}$ by AP was a necessary prerequisite for promoting AuNR growth. Furthermore, different amounts of AP-labeled secondary Abs were mixed with a fixed amount of Vc sodium phosphate and incubated at a certain temperature to generate different amounts of $V c$, which then produced AuNRs with different aspect ratios, colors, and UV absorption spectrum, which can be used as the basis for visual detection. Figure 3 shows the effect of adding different volumes of AP-goat anti-mouse IgG enzyme-labeled secondary Ab on the growth of AuNRs. With the increase in the amount of enzyme-labeled secondary Ab, the color of the mixed solution gradually became darker, from colorless to reddish brown. The UV absorption spectra showed that the longitudinal absorption peak of the prepared AuNRs had a significant red shift. There was a good linear relationship between the amount of AP 
goat anti-mouse IgG conjugated secondary $\mathrm{Ab}(40-80 \mu \mathrm{L})$ and the longitudinal absorption peak of the AuNRs produced $\left(R^{2}=0.995\right)$ (Figure 3b).

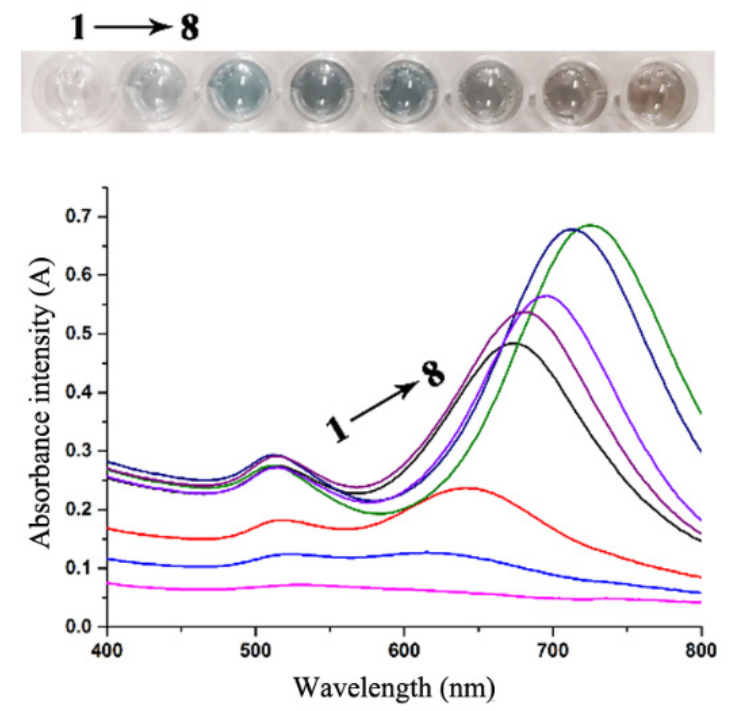

(a)

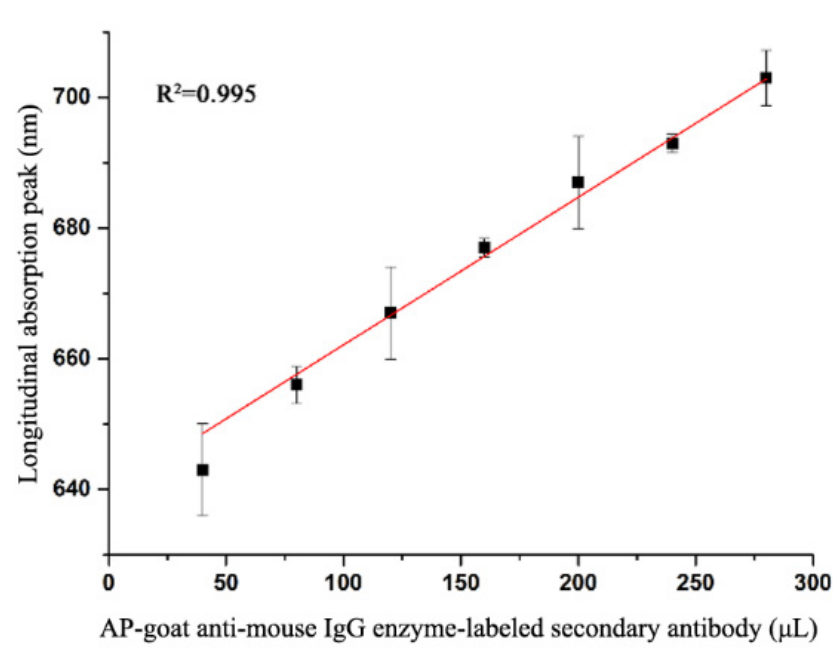

(b)

Figure 3. (a) UV-visible absorption spectra of AuNRs grown with different volumes of AP-labeled secondary Ab; (b) the standard curve of AP-labeled secondary $\mathrm{Ab}$ and longitudinal absorption peaks of AuNRs.

Transmission electron micrographs (TEM) of AuNRs prepared with the addition of 120 and $280 \mu \mathrm{L}$ of enzyme-labeled secondary Abs are shown in Figure 4 . The size of the AuNRs prepared with $120 \mu \mathrm{L}$ of enzyme-labeled secondary Ab were uniform and moderate, with an average aspect ratio of 3.5 (Figure $4 \mathrm{a}, \mathrm{b}$ ). When $280 \mu \mathrm{L}$ of enzyme-labeled secondary $\mathrm{Ab}$ was used, the aspect ratio of AuNRs increased to 4.5 (Figure 4c,d). The results showed that the addition of AP goat anti-mouse IgG enzyme-labeled secondary Ab had a direct effect on the increase in the AuNRs aspect ratio. The color and UV-visible absorption spectrum of the mixed solution showed a linear relationship with the content of AP goat anti-mouse IgG enzyme-labeled secondary Ab, indicating the feasibility of developing a visual multicolor ELISA.

\subsection{Standard Curve of AuNPs Growth-Based Multicolor ELISA for ZEN Detection}

The results of multicolor ELISA based on AuNR growth for ZEN at different concentrations (0-200 $\mu \mathrm{g} / \mathrm{L})$ are illustrated in Figure 5. The mixed solution without the addition of ZEN standard had a distinct brownish red color. As the content of ZEN increased, the color of the mixture became lighter, from dark gray to green to colorless. When the ZEN concentration was $0.1 \mu \mathrm{g} / \mathrm{L}$, the mixed solution showed a color change that can be recognized by the naked eye (from brownish red to dark gray), which meant the limit of detection (LOD) of the developed AuNRs growth-based multicolor ELISA for ZEN was lower than $0.1 \mu \mathrm{g} / \mathrm{L}$. The UV absorption spectra showed that the longitudinal absorption peak of AuNRs shifted to blue gradually with the increase in ZEN concentration. (Figure 5a). As shown in Figure 5b, ZEN concentration had a good linear correspondence with the longitudinal absorption wavelength of the corresponding AuNRs in the range of $0.001-100 \mu \mathrm{g} / \mathrm{L}$, which strongly demonstrated the potential applicability of the developed visual multicolor ELISA based on AuNRs growth for naked identification of low concentrations of mycotoxins. 


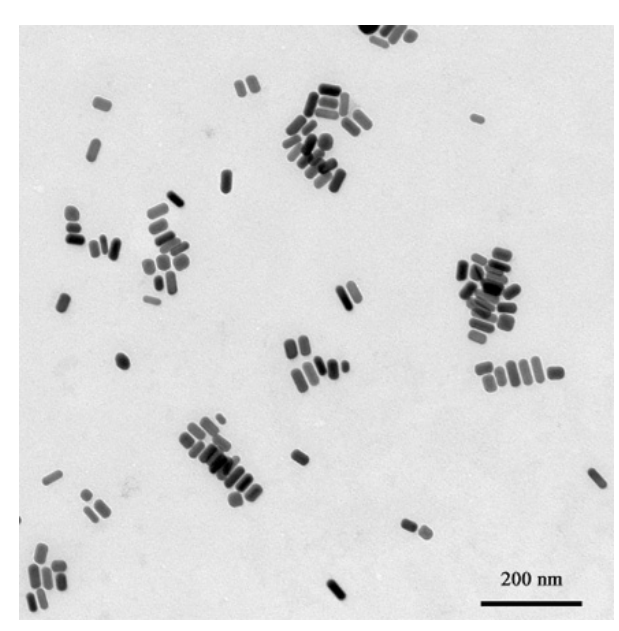

(a)

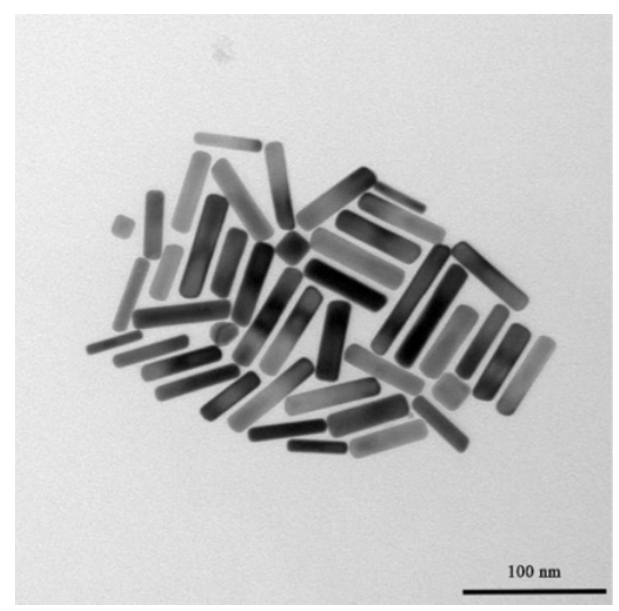

(c)

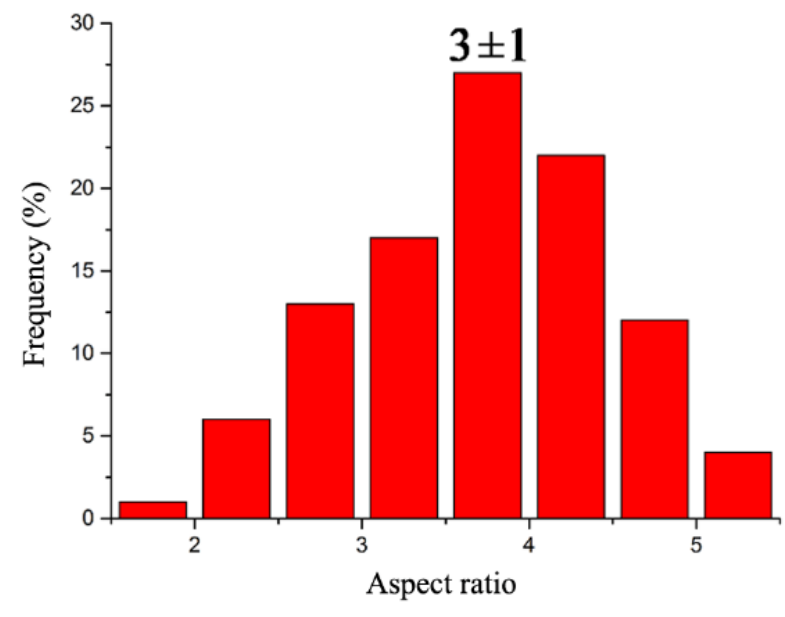

(b)

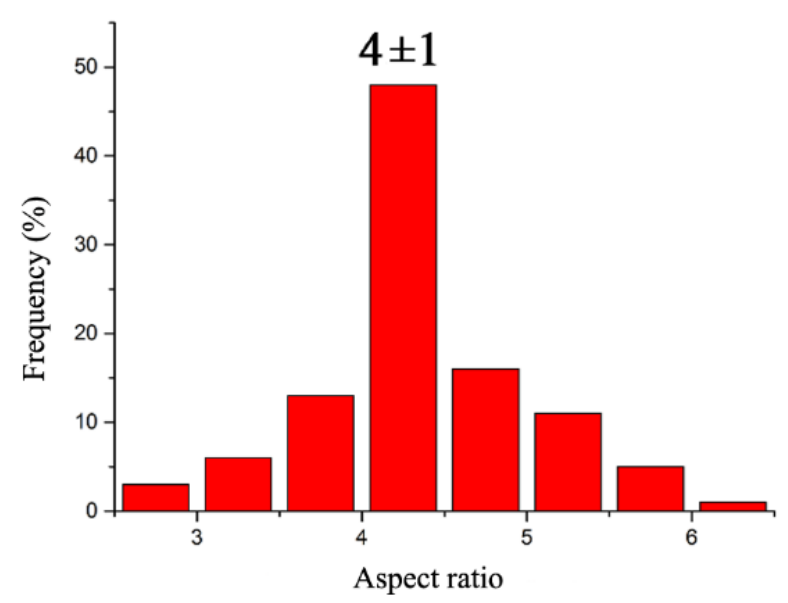

(d)

Figure 4. TEM images and aspect ratio of particle size analysis of AuNRs prepared by adding $120(\mathbf{a}, \mathbf{b})$ and $280 \mu \mathrm{L}(\mathbf{c}, \mathbf{d})$ of enzyme-labeled secondary Abs.

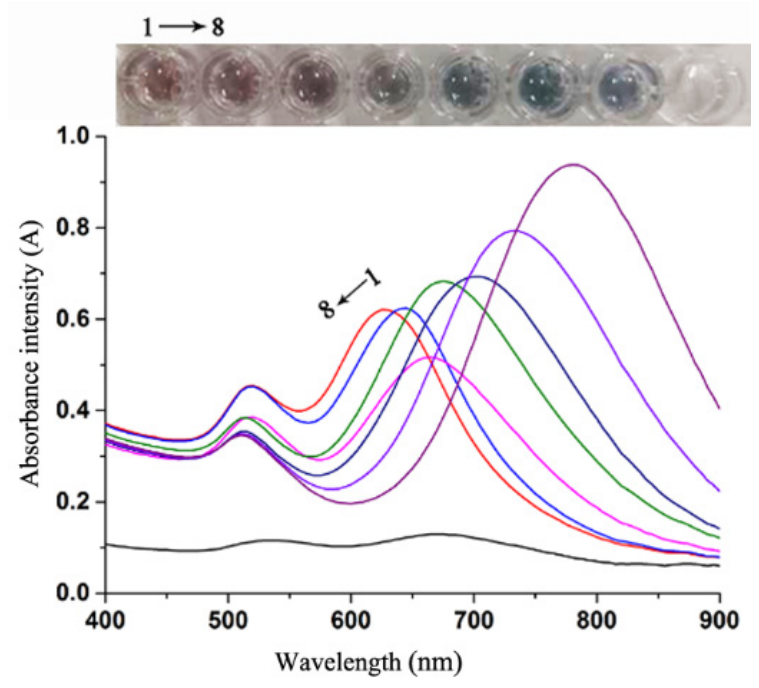

(a)

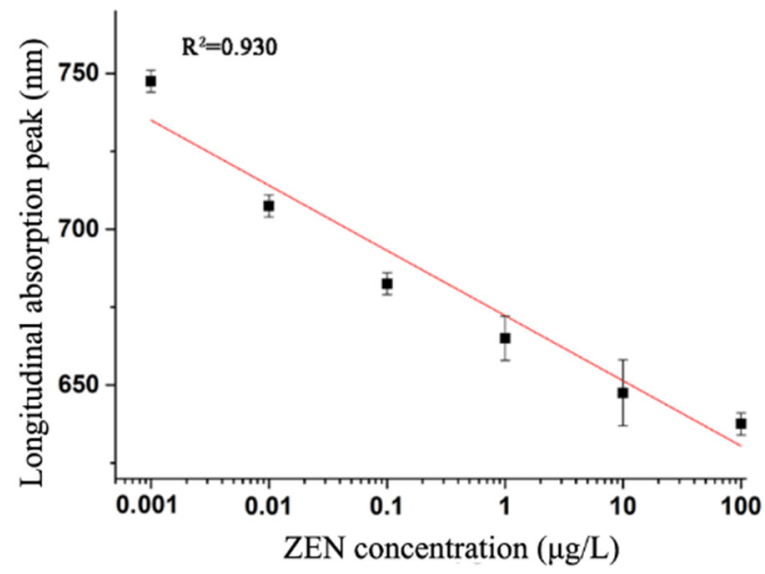

(b)

Figure 5. (a) UV absorption spectra and visual results of AuNR growth-based multicolor ELISA; (b) Standard curve of different ZEN concentration and AuNR longitudinal absorption peak. 


\section{Conclusions}

This study developed two detection strategies for the ZEN toxin based on the specific reaction of antigen-antibody. The established ic-ELISA method had high accuracy, sensitivity, and specificity, and can provide an effective semiquantitative analysis strategy for ZEN contaminants in food. The visual analysis strategy based on the growth of AuNRs was suitable for the rapid screening of a large number of contaminated samples ZEN and can be extended to the monitoring and control of the content of other harmful substances in foods. In Table 2, various reported ZEN detection strategies are illustrated to demonstrate the merits of the developed two methods in this study.

Table 2. Comparison of the published traditional instrumental and immunoassays for ZEN detection.

\begin{tabular}{|c|c|c|c|}
\hline Method Applied & Materials & Limit of Detection & References \\
\hline GC-MS & - & $5 \mathrm{ng} / \mathrm{g}$ & [15] \\
\hline LC-MS/MS & - & $0.02 \mathrm{ng} / \mathrm{mL}$ & [18] \\
\hline $\begin{array}{c}\text { Lateral flow } \\
\text { immunochromatographic assays }\end{array}$ & $\begin{array}{l}\text { Colloidal gold, quantum dots, } \\
\text { polystyrene microspheres }\end{array}$ & $10,1,1 \mu \mathrm{g} / \mathrm{L}$ & [22] \\
\hline $\begin{array}{l}\text { Fluorescence-linked } \\
\text { immunosorbent assay }\end{array}$ & $\mathrm{CdTe} / \mathrm{CdS} / \mathrm{ZnS}$ quantum dots & $0.012 \mathrm{ng} / \mathrm{mL}$ & [27] \\
\hline $\begin{array}{c}\text { Multiplexed } \\
\text { immunochromatographic assay }\end{array}$ & $\begin{array}{l}\text { Dual CdSe } / \text { ZnS quantum dot } \\
\text { nanobeads }\end{array}$ & $10 \mathrm{ng} / \mathrm{mL}$ & [31] \\
\hline ic-ELISA & - & $0.22 \pm 0.08 \mu \mathrm{g} / \mathrm{L}\left(I C_{15}\right)$ & This work \\
\hline Visualized multicolor ELISA & AuNRs & $0.1 \mu \mathrm{g} / \mathrm{L}$ & This work \\
\hline
\end{tabular}

Supplementary Materials: The following are available online at https:/ / www.mdpi.com/article/10.339 0/foods10112654/s1, Figure S1: Mass spectrum of ZEN-CMO, Table S1: Results of ZEN-OVA binding to Abs, Table S2: Optimization results of the coating-antigen and Ab, Table S3: Optimization results of the blocking buffer, and Table S4: Optimization results of $\mathrm{pH}$ value of PBS buffer.

Author Contributions: T.M. and K.L. completed the experiments and organized the writing of the entire manuscript (T.M. and K.L. contributed to this article equally); X.Y. checked the language and format of the manuscript; J.Y. participated in some experiments. M.P. provided the idea and financial support for the research and completed Section 4. S.W. checked the quality of the article. All authors have read and agreed to the published version of the manuscript.

Funding: This research was funded by the National Key Research and Development Program of China (No. 2017YFC1600402), the National Natural Science Foundation of China (No. 31972147), the Open Project Program of State Key Laboratory of Food Nutrition and Safety, Tianjin University of Science and Technology (No. SKLFNS-KF-202115), and the Natural Science Foundation of the Inner Mongolia Autonomous Region (No. 2021MS03077).

Institutional Review Board Statement: Not applicable.

Informed Consent Statement: Not applicable.

Data Availability Statement: The datasets generated for this study are available on request to the corresponding author.

Conflicts of Interest: The authors declare no conflict of interest.

\section{References}

1. Freire, L.; Sant'Ana, A.S. Modified mycotoxins: An updated review on their formation, detection, occurrence, and toxic effects. Food Chem. Toxicol. 2018, 111, 189-205. [CrossRef] [PubMed]

2. Mahato, D.K.; Devi, S.; Pandhi, S.; Sharma, B.; Maurya, K.K.; Mishra, S.; Dhawan, K.; Selvakumar, R.; Kamle, M.; Mishra, A.K.; et al. Occurrence, impact on agriculture, human health, and management strategies of zearalenone in food and feed: A review. Toxins 2021, 13, 92. [CrossRef]

3. Mazaheri, M.; Maymand, M.M.; Gilasgar, A.; Akbarzadeh, A.; Manafi, M.H. Quantification of the zearalenone in maize oil with no clean-up. Food Control 2021, 127, 108166. [CrossRef] 
4. Zinedine, A.; Soriano, J.M.; Molto, J.C.; Manes, J. Review on the toxicity, occurrence, metabolism, detoxification, regulations and intake of zearalenone: An oestrogenic mycotoxin. Food Chem. Toxicol. 2007, 45, 1-18. [CrossRef]

5. Yu, Z.; Zhang, L.; Wu, D.; Liu, F. Anti-apoptotic action of zearalenone in MCF7 cells. Ecotox. Environ. Saf. 2005, 62, 441-446. [CrossRef]

6. Rai, A.; Das, M.; Tripathi, A. Occurrence and toxicity of a fusarium mycotoxin, zearalenone. Crit. Rev. Food Sci. 2020, 60, 2710-2729. [CrossRef]

7. Sneha, S.; Baker, S.C.; Green, A.; Storr, S.; Aiyappa, R.; Martin, S.; Pors, K. Intratumoural Cytochrome P450 expression in breast cancer: Impact on standard of care treatment and new efforts to develop tumour-selective therapies. Biomedicines 2021, 9, 290. [CrossRef] [PubMed]

8. Yu, Z.L.; Hu, D.; Li, Y. Effects of zearalenone on mRNA expression and activity of cytochrorne P450 1A1 and 1B1 in MCF-7 cells. Ecotox. Environ. Safe. 2004, 58, 187-193. [CrossRef]

9. Rogowska, A.; Pomastowski, P.; Sagandykova, G.; Buszewski, B. Zearalenone and its metabolites: Effect on human health, metabolism and neutralisation methods. Toxicon 2019, 162, 46-56. [CrossRef] [PubMed]

10. Gajęcka, M.; Janowski, T.; Jakimiuk, E.; Zielonka, Ł.; Podhalicz-Dziegielewska, M.; Jan Obremski, K.; Gajęcki, M. Influence of long-term zearalenone intoxication on the concentration of progesterone and 17 beta-oestradiol in blood plasma in bitches. Bull. Vet. Inst. Pulawy 2008, 52, 405-409.

11. Ji, F.; He, D.; Olaniran, A.O.; Mokoena, M.P.; Xu, J.; Shi, J. Occurrence, toxicity, production and detection of Fusarium mycotoxin: A review. Food Prod. Process. Nutr. 2019, 1, 6. [CrossRef]

12. Hong, X.; Mao, Y.H.; Yang, C.Q.; Liu, Z.J.; Li, M.; Du, D.L. Contamination of Zearalenone from China in 2019 by a Visual and Digitized Immunochromatographic Assay. Toxins 2020, 12, 521. [CrossRef]

13. Pan, M.F.; Ma, T.Y.; Yang, J.Y.; Li, S.J.; Liu, S.M.; Wang, S. Development of lateral flow immunochromatographic assays using colloidal au sphere and nanorods as signal marker for the determination of zearalenone in cereals. Foods 2020, 9, 281. [CrossRef]

14. GB2761-2017. National Standard of People's Republic of China-Limitation of Mycotoxins in Food. Available online: http: // down.foodmate.net/info/sort/2/7407.html (accessed on 17 September 2017).

15. Tanaka, T.; Yoneda, A.; Inoue, S.; Sugiura, Y.; Ueno, Y. Simultaneous determination of trichothecene mycotoxins and zearalenone in cereals by gas chromatography-mass spectrometry. J. Chromatogr. A 2000, 882, 23-28. [CrossRef]

16. Amelin, V.G.; Karaseva, N.M.; Tretyakov, A.V. Simultaneous determination of trichothecene micotoxins, ochratoxin A, and zearalenone in grain and products of its processing, feed premixes, and meat by gas chromatography. J. Anal. Chem. 2013, 68, 61-67. [CrossRef]

17. Qian, M.R.; Zhang, H.; Wu, L.Q.; Jin, N.; Wang, J.M.; Jiang, K.Z. Simultaneous determination of zearalenone and its derivatives in edible vegetable oil by gel permeation chromatography and gas chromatography-triple quadrupole mass spectrometry. Food Chem. 2015, 166, 23-28. [CrossRef] [PubMed]

18. Li, C.L.; Deng, C.L.; Zhou, S.; Zhao, Y.F.; Wang, D.; Wang, X.D.; Gong, Y.Y.; Wu, Y.N. High-throughput and sensitive determination of urinary zearalenone and metabolites by UPLC-MS/MS and its application to a human exposure study. Anal. Bioanal. Chem. 2018, 410, 5301-5312. [CrossRef] [PubMed]

19. Sun, D.L.; Li, C.L.; Zhou, S.; Zhao, Y.F.; Gong, Y.Y.; Gong, Z.Y.; Wu, Y.N. Determination of trace zearalenone and its metabolites in human serum by a high-throughput UPLC-MS/MS analysis. Appl. Sci. 2019, 9, 741. [CrossRef]

20. Tahoun, I.F.; Gab-Allah, M.A.; Yamani, R.N.; Shehata, A.B. Development and validation of a reliable LC-MS/MS method for simultaneous determination of deoxynivalenol and T-2 toxin in maize and oats. Microchem. J. 2021, 169, 106599. [CrossRef]

21. Engvall, E. Enzyme-linked immunosorbent assay (ELISA), quantitative assay of immunoglobulin G. Immunochemistry 1971, 8, 871-874. [CrossRef]

22. Li, S.J.; Sheng, W.; Wen, W.J.; Gu, Y.; Wang, J.P.; Wang, S. Three kinds of lateral flow immunochromatographic assays based on the use of nanoparticle labels for fluorometric determination of zearalenone. Microchim. Acta 2018, 185, 238. [CrossRef]

23. Gemes, B.; Takacs, E.; Gadoros, P.; Barocsi, A.; Kocsanyi, L.; Lenk, S.; Csakanyi, A.; Kautny, S.; Domjan, L.; Szarvas, G.; et al. Development of an immunofluorescence assay module for determination of the mycotoxin zearalenone in water. Toxins 2021, 13, 182. [CrossRef]

24. Li, R.X.; Wen, Y.; Yang, L.Q.; Liu, A.G.; Wang, F.L.; He, P.L. Dual quantum dot nanobeads-based fluorescence-linked immunosorbent assay for simultaneous detection of aflatoxin B1 and zearalenone in feedstuffs. Food Chem. 2022, $366,130527$. [CrossRef]

25. Liu, R.X.; Shi, R.R.; Zou, W.T.; Chen, W.H.; Yin, X.C.; Zhao, F.C.; Yang, Z.Y. Highly sensitive phage-magnetic-chemiluminescent enzyme immunoassay for determination of zearalenone. Food Chem. 2020, 325, 126905. [CrossRef]

26. Fu, J.M.; Zhou, Y.F.; Huang, X.L.; Zhang, W.J.; Wu, Y.H.; Fang, H.; Zhang, C.Z.; Xiong, Y.H. Dramatically enhanced immunochromatographic assay using cascade signal amplification for ultrasensitive detection of Escherichia coli O157: H7 in milk. J. Agric. Food Chem. 2020, 68, 1118-1125. [CrossRef] [PubMed]

27. Zhang, F.Y.; Liu, B.; Sheng, W.; Zhang, Y.; Liu, Q.; Li, S.J.; Wang, S. Fluoroimmunoassays for the detection of zearalenone in maize using CdTe/CdS/ZnS quantum dots. Food Chem. 2018, 255, 421-428. [CrossRef] [PubMed]

28. Xiong, Y.; Pei, K.; Wu, Y.Q.; Duan, H.; Lai, W.H.; Xiong, Y.H. Plasmonic ELISA based on enzyme-assisted etching of Au nanorods for the highly sensitive detection of aflatoxin B-1 in corn samples. Sens. Actuators B Chem. 2018, 267, 320-327. [CrossRef] 
29. Liu, Z.J.; Wang, X.Y.; Ren, X.X.; Li, W.B.; Sun, J.F.; Wang, X.W.; Huang, Y.Q.; Guo, Y.G.; Zeng, H.W. Novel fluorescence immunoassay for the detection of zearalenone using HRP-mediated fluorescence quenching of gold-silver bimetallic nanoclusters. Food Chem. 2021, 355, 129633. [CrossRef]

30. Thouvenot, D.; Morfin, R.F. Radioimmunoassay for zearalenone and zearalanol in human serum: Production, properties, and use of porcine antibodies. Appl. Environ. Microb. 1983, 45, 16-23. [CrossRef] [PubMed]

31. Duan, H.; Li, Y.; Shao, Y.N.; Huang, X.L.; Xiong, Y.H. Multicolor quantum dot nanobeads for simultaneous multiplex immunochromatographic detection of mycotoxins in maize. Sens. Actuators B Chem. 2019, 291, 411-417. [CrossRef] 